\title{
Towards an Intermedial Ecocriticism
}

\author{
Jorgen Brubn
}

\section{Contents}

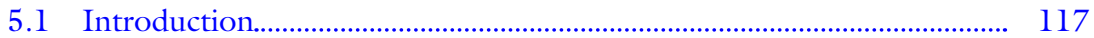

5.2 Sketching the Background............................................................................. 119

5.3 Comparative Case Study........................................................................... 129

5.4 Concluding Remarks........................................................................................ 143

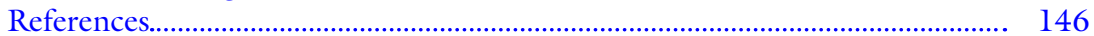

\section{$5.1 \quad$ INTRODUCTION}

Let me begin with a question. What, if anything, unites the following three, very different, media products: a scientific article called "Trajectories of the earth system in the Anthropocene" by Will Steffen and his colleagues (Steffen et al. 2018), which discusses aspects of what the authors call the Anthropocene epoch; Chinese director Zhao Liang's semidocumentary film, Behemoth (2016), which depicts the effects of coal and mineral extraction in China; and, finally, the collection of short stories $I$ am with the Bears (Atwood et al. 2011)? Apart from being written,

J. Bruhn $(\bowtie)$

Linnaeus University, Växjö, Sweden

e-mail: jorgen.bruhn@lnu.se

(C) The Author(s) 2021

L. Elleström (ed.), Beyond Media Borders, Volume 2, https://doi.org/10.1007/978-3-030-49683-8_5 
produced, and published within a few years of each other, the obvious common denominator is that they all respond to and in different ways aim to represent different aspects of the current planetary ecological crisis as defined by, among others, atmospheric chemists, climate scientists, and geographers. They are part of the broad field of ecomedia that I will define later.

To put it very briefly, the natural sciences work by meticulously collecting data, which are often based on measurements taken by sophisticated technical apparatuses, in and outside laboratory facilities. The data are, since the massive breakthrough of immensely strong computing powers, analysed by way of the now ubiquitous computer simulations (Roundtree 2014). This enables scientists to produce descriptions of extremely complex conditions not only as they are at the present moment but also in relation to the past and the future and, in the case of ecologically related threats, the data are used to predict future scenarios. Most of such work and the discussions around it take place in the confined spaces of academic journals and scientific conferences, and this is how most non-specialists get to know about scientific results and research-via printed or digital or other media forms, often in relation to fairly 'spectacular' breakthroughs or particularly frightening predictions.

In other words, for the natural scientific results to make any impact outside the relatively narrow circles of scientific publications and debate, the results need to be communicated, and communication per se involves media products with different possibilities and limits. Newspapers, popular science journals, and documentaries are some of the well-known media forms that communicate information about scientific research, but poetry, science fiction novels, feature films, or art exhibitions can do this too. That the results of scientific research need to be communicated to the public is, of course, a known fact in several well-developed disciplines, including risk communication, health communication, science communication, and climate change communication studies. ${ }^{1}$ These fields are based on a tradition of communication studies which are particularly well suited to analyse the history and impact of journalistic media and mass medial forms, but that have not traditionally been interested in aesthetic communication.

In this chapter I will, like these fields would normally try to, take as the crucial, rather commonsensical, starting point that it is indeed media products-three examples of which I mentioned to begin with-that communicate basic ideas about the ecological condition of the planet to most people. I agree with these fields that it is important to investigate 
these on a sound theoretical and methodological basis, but, in my readings in the field, I have not yet come across a satisfying theory or method which describes and analyses (and thus compares) media products from the perspective of the broad spectrum of the communication of science that goes all the way from, for instance, the United Nations' Intergovernmental Panel on Climate Change (IPCC) reports to a science fiction feature film, a newspaper article, or a board game representing the ethical problems that are emerging from a warming world. Or the three examples mentioned in my introduction above.

It is my aim, in this chapter, to suggest a theory and method that are able to do exactly this: I call this position 'intermedial ecocriticism', and the most general idea of intermedial ecocriticism is the conviction that the ecological crisis is not a problem or a condition restricted to investigations in the natural sciences, or that possible solutions to the crisis can be reduced to technological solutions. The humanities need to play a role in the question.

\subsection{Sketching THE BACKGround}

The immediate problem of analysing and comparing the three examples mentioned above is that they clearly fall into three very different categories. In the intermedial research tradition I belong to, the three examples are called "media products", and they quite clearly belong to three different "qualified media types" (Elleström 2010, 2020). It is the fundamental differences in qualified media types that make it hazardous to make wellfounded critical comparisons between them, unless the three different media are simply, and quite crudely, considered to be different boxes containing the same content. This is probably why the communication fields mentioned above have mostly refrained from making more substantial comparisons across media borders. Therefore, the question is which options are available if the ideas concerning the ecological crisis, as these are represented in a wide array of media forms, are to be analysed in a fruitful way.

In this chapter, I argue that it is possible and even necessary to combine two academic disciplines, intermedial studies and ecocriticism, in order to face the challenge of analysing, discussing, and comparing texts like the three examples mentioned. Instead of using the communication studies approach, which has mostly been developed on social sciences 
foundations, I have been looking for suitable theoretical foundations in what is often called the 'environmental humanities' or 'green humanities'.

I work from the hypothesis that, in general, the environmental humanities tradition is haunted by a methodological impasse, in that it often tends to do one of two things. The first is that in terms of media types, and thus academic disciplines, there is a tendency to 'compartmentalize' ecological questions, as if the ecological crisis respects the borderlines defined by media types or academic departmental traditions. The second is that when cultural theorists with broader interests that span different media types and academic disciplines examine ecological representations, they often do so, I will argue, without a sound methodological and theoretical ground: it takes a well-defined common ground to compare, say, a scientific article with a science fiction film. This is why, in what follows, I argue that the environmental humanities could be supplemented with an analytical tool that is sufficiently broad to analyse several media types and sufficiently fine-grained to do this in a detailed way.

I do not wish to give the impression that there are currently no environmental humanities approaches that go in this direction, though. One such approach has been suggested by the cognitive cultural scholar Alexa Weik von Mossner. In an attempt to overcome some of the problems inherent in the field, she recently defined "environmental narratives" as "any type of narrative in any media that foregrounds ecological issues and human-nature relationships, often but not always with the openly stated intention of bringing about social change" (Weik von Mossner 2017: 3). This very broad definition (depending on how widely the notion of narrative is defined) may be compared with one of the shortest but, at the same time, most comprehensive definitions of ecocriticism, which has been provided by the influential literary ecocritic Gregg Garrard. Ecocriticism, for him, is "the study of the relationship between the human and the nonhuman, throughout human history and entailing critical analysis of the term 'human' itself" (Garrard 2012: 5). Garrard's and von Mossner's definitions are valuable because they open a possible perspective of a broad environmental investigation across media, as opposed to the many productive attempts to analyse environmental questions in one, single media type, not only in literature (the originating and still-dominating discipline in ecocriticism) but also in a number of other aesthetic media. ${ }^{2}$ However, even if these descriptions raise the hope of a truly cross-disciplinary ecocritical approach that can be adopted across, in principle, all imaginable media types, it has not really been fulfilled yet. In von Mossner's study, 
which is built upon a cognitive narratological foundation, the admirably broad corpus is restricted to fictive and non-fictive literary and cinematic narratives. And even if Garrard's definition is potentially cross-medial, his own corpus is mostly literary material.

What is needed, I argue, is an approach that can analyse and compare media products across, in principle, all media types and, for this purpose, the term 'ecomedia' has been proposed. Since this suggestion lies close to my own interests, I will discuss this position in some detail. According to Simon Estok, the term includes "any media that deals with environmental issues, implicitly or explicitly". It is a reference to 'Ecomedia studies', defined by Stephen Rust as "a historically situated, ideologically motivated, and ethically informed approach to the intersections, of media, society, and the environment" (quoted in Estok 2017: 17). The notion of ecomedia studies is clearly affiliated with my idea of intermedial ecocriticism, but there are major differences. The field is described in the anthology Ecomedia (Rust et al. 2016), which defines itself as a textbook (it includes working questions and fact boxes). It offers a broad survey of qualified media types, including photography, cinema, advertising, new media, and gaming, as well as other, mostly mass medial forms, which are discussed under three headings. "Frames" deals with visual media, "Flow" deals with broadcast media, and "Convergence" deals with the mixing and transforming of mostly non-aesthetic 'new' media in contemporary culture.

Ecomedia offers an admirable up-to-date discussion of crucial aspects of ecocritical discussions regarding a number of qualified media types across the globe. However, the book refrains from defining media, mediality, or mediation in any sustained form (it does not do so in the general introduction to the book nor in the three opening chapters that define Frames, Flow, and Convergence). As a result, the book provides ten well-structured and very informative medium-specific descriptions of specific media forms' ways of relating to environmental questions through engaged case studies, but does not formulate general notions that enable comparisons and discussions across the borders of different media types. So, what the book admirably gains in flexibility, global breadth, and illuminating examples, it lacks in systematicity and thus comparability. In what follows, ecomedia refers to the entire corpus of representations dealing with ecological issues, but it does not refer to any particular theory or analytical method. Regarding intermedial terms, I use the term 'ecomedia' to signify representations of environmental issues in any specific media product that in 
any qualified media type engage in representing in fiction or non-fiction (or mixing these) either the reasons behind or the results of the environmental threats; Ecomedia representations include the notion of the effects of what has been called the Anthropocene epoch, which necessarily includes a questioning of the distinctions between human and non-human, and between culture and nature.

In respectful but critical opposition to the Ecomedia position, I will suggest a cross-medial ecocritical approach, where media products from a wide range of media types could not only be analysed but also critically compared in meaningful ways. But what would such a method look like?

My fundamental suggestion seems simple: I wish to investigate the broad corpus of ecomedia by applying intermedial terminology. That is, I aim to show that the rich and deep insights of contemporary ecocritical thinking can be combined productively with the analytical strengths of intermedial studies. As mentioned above, this is what I call intermedial ecocriticism.

\subsubsection{Three Basic Intermedial Points-And the Question of Representation}

I will refrain from setting out in any detail Elleström's notion of the four modalities of media or the distinctions between basic media types, qualified media types, and technical media of display, which are all clearly explained in Elleström (2020). Elsewhere, I have constructed an analytical model based on Elleström's ideas (Bruhn 2016; Bruhn and Gjelsvik 2018). What I do want to stress is that Elleström's modelling of media makes it possible to gain a fundamental understanding of three basic intermedial ideas that I consider to be part of the essential infrastructure of intermedial studies. The first idea is that all media products are medially and modally mixed, which of course is an idea that other researchers have been well aware of but have often described in more intuitive ways (Mitchell 1994; Bruhn 2010). It is tempting to jump to the conclusion that this would mean that there are no such things as media types (or genres, or other comparable categories), but this is not the case: almost all media products are, according to their definition, part of a qualified media type, but these types are not only defined by their constellation of media and modalities; they are also contextually and operationally defined. The second idea, therefore, involves talking about a contextualized medium specificity, meaning that despite the mixedness of media, all media 
products, according to their definition, can be characterized with a weak, so to speak, or temporary medium specificity: any qualified media type offers temporary "affordances", that is, limits and possibilities (Kress 2010) that enable some things to be expressed and hinder other things being expressed. The third, general intermedial idea is that, apart from having a descriptive analysis and contextualized definition of the basic media aspects, it is also useful to work with a key analytical distinction between media integration and media transformation. ${ }^{3}$

This distinction is a result of the a prioric idea of intermedial studies, namely that all media are medially and modally mixed, which naturally leads to the question of how the a prioric mixedness of all media texts may be analytically approached. It is not particularly interesting to simply demonstrate the mixedness of media products; instead, the mixedness needs to be described and analysed. From an analytical, pragmatic point of view, the most important dimensions are media integration and media transformation-the transformation dimension is particularly important in intermedial ecocriticism.

Broadly but briefly speaking, the media integration perspective applies to phenomena where two or more medial forms or modes coexist in the same media product at the same time. Examples could be if a painting by Cézanne is represented in a film and jazz is playing in the background or when images and written words coexist as parts of a scientific article. On the other hand, the media transformation perspective investigates how medial content or form is transformed from one medium to another in a temporal process. For instance, when a scientific idea (like oxygen) is drawn as connected atoms on a blackboard in a classroom, when a novel by Jane Austen is turned into a film, or when the idea of climate change, as expressed in scientific articles, is represented as the main theme in a contemporary environmental documentary or a feature film.

Media transformation, according to its definition, contains a temporal perspective. First there is a novel, then it is turned into a film; first there is film, then it is turned into an amusement park; first there is a painting, then there is a poem representing this painting, and so forth. In this large corpus of cultural objects and processes, introduced and discussed in Linda Hutcheon's A Theory of Adaptation (Hutcheon 2006; see also Bruhn et al. 2013), the medial mix lies, so to speak, in the process: certain aspects of a novel (typically, themes, parts of the plot, certain characters, setting, etc.) are transported into a film, but certain aspects of the adapted work are necessarily left out or changed beyond recognition. The media 
transformation process is transferring certain aspects while also transforming everything into a new media product (and a different technical and qualified medium). Analysing media transformation basically means understanding the interplay between medium specificity (what characterizes specific media) and transmedial aspects (that which crosses media borders).

From an analytical point of view, it is helpful to divide all the inherent mixedness of all media products into either 'temporal transformation' or 'synchronous integration', but this distinction is pragmatic rather than essential. Given the idea that all medialities are mixed, it follows, on the one hand, that all media products are in fact an integration of mediality or modality aspects. Given the fundamental idea of intertextuality, meaning that all texts are versions of earlier texts (Allen 2011), on the other hand, we may conclude that all medialities are, basically, the result of a transformation.

Consequently, when performing an intermedial analysis on a specific media product or on the relations between media products (or when thinking about the general aspects of a media type), one might investigate either mixtures (integration) or traces (transformation). Thus, from a medial perspective, any media product, for instance, a literary text, is comparable to the famous duck-rabbit illusions: depending on your analytical interest and investment, you can choose to perceive a media product either as a combination or as a process of transformation; both dimensions are inherent aspects of the specific media product. To get the fullest possible description and interpretation, one might combine the two approaches, but many specific analyses will typically focus on one of the two dimensions.

At this point in my demonstration of the general analytical notions, I need to touch upon the question of representation, more particularly the representation of environmental issues, which has been a central concern in contemporary environmental humanities. Rob Nixon is an important commentator on this question, and he stresses the "formidable representational obstacles" of describing global warming (Nixon 2011: 2). He also underlines that the effects of the ecological crisis, which he usefully and famously terms "slow violence", is "a violence that is neither spectacular nor instantaneous, but rather incremental and accretive, its calamitous repercussions playing out across a range of temporal scales" (Nixon 2011: 2 ). This means, basically, that the dramatic effect of the ecological crisis in general, and global warming specifically, is a phenomenon that is imbued with a set of complicated representational issues. In recent ecocriticism 
concerning the representations of global warming, Timothy Morton's idea of the 'hyperobject' (Morton 2013) has been perhaps too influential in convincing critics of the near-impossible task of understanding and therefore representing climate change as well as other aspects of the ecological crisis. ${ }^{4}$ I intend to follow Nixon in acknowledging that the environmental crisis presents huge problems of both grasping and representing the crisis, but I do not find it useful to consider, for instance, global warming to be an unrepresentable hyperobject.

I prefer a more pragmatic understanding of the abilities of representation. Representation, as I see it, is a fundamental part of human communication: it is a process that uses media products to stand in for all sorts of phenomena of material or mental character, including so-called fictive and non-fictive phenomena. According to their definition, representations cannot be completely identical to what they represent, and representation is not devoid of performative aspects, so any representations necessarily function on a differentiating scale from higher to lower precision and effect, depending not only on the media products but also on the context in which the media products are produced and perceived. Language, visual communication, and any other semiotic forms of representation are often very efficient but not impeccable tools of communication. In principle, I do not wish to exaggerate the fundamental differences in how easy, or difficult, it is to represent the coffee cup on the table beside me as I write these lines as compared to the effects of climate change or the victims of the so-called sixth mass extinction (for a broad discussion of the question of representation, see Hall et al. 2013).

Let me try to sum up the first, general part of my exposition. Intermedial ecocriticism is intended to mark the outline of a broad-spectrum research goal. The most general background of intermedial ecocriticism is the conviction that the ecological crisis is not a topic restricted to investigations in the natural sciences, or that solutions to the crisis can be reduced to any quick tech fix. Instead, as environmental humanities stresses time and again, the ecological crisis relates to key questions that the humanities ask and, consequently, ecological issues are "being reimagined as an ethical, societal, and cultural problem" (Yusoff and Gabrys 2011: 517). Or, to use a slightly longer quote from Ursula Heise's 2017 introduction to a large handbook on environmental humanities:

The environmental humanities, by contrast [to the technico-scientific approach], envision ecological crises fundamentally as questions of socio- 
economic inequality, cultural difference, and divergent histories, values, and ethical frameworks. Scientific understanding and technological problem-solving, essential though they are, themselves are shaped by such frameworks and stand to gain by situating themselves in this historical and sociocultural landscape. (Heise et al. 2017: 3)

Intermedial ecocriticism, more specifically, contributes to the explorations in ecocriticism and environmental humanities by stressing that ecological questions, according to their definition, relate to questions of communication and thus representation, and by stressing in particular that environmental humanities and ecocriticism need a cross-disciplinary and cross-media analytic approach that matches the necessarily broad nature of the environmental crisis.

By using the notion of intermedial ecocriticism, I aim to develop a method to analyse and interpret specific media products, or, on welldefined methodological grounds, to compare more than one media product across media borders.

In other words, this is the broad outline of some of the outcomes that an intermedial approach to ecocritical questions may achieve, but it is important to stress that combining the field of intermedial studies with ecocriticism (or other fields inside environmental humanities) may lead to several rather divergent approaches. How ecocriticism and intermedial studies are combined depends, for instance, on the specific scientific or even ideological interests of the researcher: it depends on which audiences are meant to receive the results and whether the research idea is meant to be used in didactic contexts. In what follows, I sketch out one among many possible operational approaches of intermedial ecocriticism.

\subsubsection{Intermedial Ecocriticism: A Methodological Suggestion}

The obvious initial move, before any analysis is even begun, is to choose one or more media products with subject matters that relate to ecological issues. In short, the media products should be part of the corpus of ecomedia. This must be followed by choosing a specific question or problem to investigate in the chosen media product(s). Topics to investigate can be anything from the representation of the ecological 'crisis' to narrative aspects of the ecomedia product, to the ways in which the media product facilitates human agency in the Anthropocene, to temporal patterns in Anthropocene representations. Or, and here I am referring to existing 
ecocritical work, one can discuss whether and how the existential and psychological notion of 'pretrauma' exists in cinema and literature (following Anne E. Kaplan 2015), or different affective patterns in narrative as well as non-narrative media products (following Weik von Mossner 2017). It will come as no surprise that the initial choice of topic has important consequences, because it will direct the analysis of the media product (and if one works with more than one media product, the chosen topic will be the one that is being compared). To explain the approach, in what follows, I will use an imagined ecomedia product: a short, printed newspaper article which describes the melting glaciers in the Arctic, and the topic I want to explore will be examined by asking this question: how, in intermedial terms, are the melting glaciers represented in this article?

After the initial choice of media product(s), as well as one or more topics to be analysed and perhaps compared, three consecutive steps follow: in the first, descriptive step, the main aim is to define and analytically describe the fundamental features of the media type in general and the media product in particular. In the second step, after having established the basic features, the aim is to specify, by way of an analysis and interpretation, the exact ways in which the affordances of the media product enable or disable specific aspects that are to be represented. In the third and final step, the results of the analysis can be compared to the analysis of one or more media products.

In the analysis, I apply the descriptive media tools suggested by Elleström (2020), but let me again emphasize that the general features of the approach I have sketched out can be followed by using other analytical tools that facilitate analysis of texts and comparative investigation. There is a more detailed description below of the three-step working processes.

\section{Step 1}

Step 1 consists of, first, carrying out a descriptive analysis of the (often obvious) technical media of display that characterizes the chosen media product; here the researcher can choose the media of display through which he or she has received the media product, or the researcher can describe the typical or most widespread display function for the specific media product. With regard to my example, in the short article on the melting Arctic ice caps, the technical media of display is a paper version of a newspaper (or the internet version of this article, which would make the technical media of display the computer screen or the mobile phone screen). I will refer to the paper version here. 
After this, what Elleström defines as the material, spatiotemporal, sensorial, and semiotic categories of the basic media dimension of the media product are described. The basic media aspects of the newspaper article that I take as an example would be that the material aspect would include paper and ink: the spatiotemporal aspect would include the fact that the conventional way to read the article would be to read the text in the sequence produced by the journalist, even though it is possible, with a written text, to read it in your own preferred way. In sensorial terms, a printed article is predominantly perceived through the eyes, and the fundamental semiotic aspect of the newspaper article would include the fact that the verbal written text is mainly interpreted by way of its symbolic sign qualities; if there are photographs in the article, these would relate more to an iconic sign function (both aspects are interpreted according to Peircean semiotics).

The aim of the first step is to establish a precise and detailed description which will enable the next step's more interpretative actions. The description is meant to result in a clear understanding of the different medial aspects of a text, which therefore makes the following interpretive moves easier-and, if necessary, it makes the comparison between media products possible.

\section{Step 2}

Having established the qualified media type, the aim of step 2 is to analyse and interpret the media product using intermedial analytical tools. The media integration and/or the media transformation perspective can be applied, as well as other intermedial analytical and descriptive tools. The aim of the analysis is to specify the affordance of the qualified media type as this plays out in the specific ecomedia product regarding its ability to represent ecological topics. Generally, the media transformation aspect will loom large in many intermedial ecocritical analyses because all ecomedia products are fundamentally, from an intermedial point of view, media transformations of scientific material into ecomedia.

So, regarding the short, printed newspaper article mentioned above, from a media transformation angle it is an example of how a scientific measurement of ice caps, which has first been published in a natural scientific article, has been transferred and transformed by a journalist into the format of a news item. The interplay between the photograph and the written text of the article can be analysed from the media integration perspective. 
The aim of this analysis is to understand which aspects of, in this case, global warming, as this affects the Arctic ice caps, a short newspaper article generally, and the chosen article specifically, can represent. To a certain extent, the analysis may confirm rather commonsensical and general conclusions, but the advantage of the analysis is that it can be much more precise in pinpointing the exact affordances of the general media type and the specific media product. In my more extended examples below, I will demonstrate the usefulness of this step.

\section{Step 3}

Having established the specific affordances of the given media product, step 3 allows the possibility of comparing it with other media products with a directly comparable subject matter. If this step is taken, then the second, or third, or fourth media product must of course be subjected to the two steps described above before conducting the third, comparative step.

\subsection{Comparative Case Study}

\subsubsection{A CarbonBrief Article}

Having explained the mechanics of my method by way of an imagined example, I now wish to do a comparative case study of two actual existing ecomedia products.

The specific topics I wish to pursue are as follows:

(a) How, from an intermedial point of view, do the media products represent scientific research related to global warming?

(b) How, from an intermedial point of view, do the media products employ strategies that make hard science directly related to the everyday experience of non-experts in climate science?

The first ecomedia product I wish to analyse was published in August 2019 on the website of CarbonBrief, which is an internet-based, factoriented media outlet situated in London. CarbonBrief publishes articles, comments, and other material related to global warming issues on the internet but not on paper: there is often a focus on aspects related to the UK, but the work has a clear global outlook. Material published on the site is based on new events relating to global warming, either events in the 
world or scientific reports or new findings. The article I will analyse was written by Daisy Dunne and is called "Climate change made Europe's 2019 record heatwave up to " 100 times more likely" and was published on the website on 2 August 2019 (Dunne 2019).

The general aim of this popular scientific article, which consists of about 1500 words, one photograph, and two modified maps of Europe, is to represent to its readers the scientific hypothesis that the global temperature on the planet is rising due to anthropogenic influence. More specifically, the article argues that different dramatic results of this new planetary condition can be analysed in a new and more exact way by means of socalled attribution science. Attribution science has advantages compared to more traditional climate science, which has been very cautious regarding linking actual weather phenomena with climate change. The aim of attribution science is to link much more directly the concrete and often dramatic weather phenomena with more general developments in the climate, typically by saying that a certain dramatic weather phenomenon has been made $x$ times more plausible due to the larger effects of climate change.

The question is, how does the article do this-and can it be meaningfully compared to other media products with approximately the same aim?

\section{Step 1}

Given the fact that CarbonBrief is a web-only publication, any reading of the text will be done via a screen, either on a computer (that is how I read it) or on a mobile phone. In my reading of the text, the technical medium of display is therefore a laptop computer screen.

The material aspect of the article, as displayed on a computer screen, is the two-dimensional space upon which one can read text and see images by way of the technical apparatus making things visible on a screen, for instance, by scrolling on the page. An internet connection is also necessary to be able to reach the website. Several colour photos and/or colour data visualizations are a natural part of all the articles on the CarbonBrief website, and these also form part of the material aspect. The cost of reproducing images is much lower for online publications than for printed articles, so there tend to be more in the former.

In this case, there is a large colour photograph documenting a man shielding himself with a newspaper during the heatwave in London in July 2019 and two visualizations of historical heat patterns in Europe.

The spatiotemporal organization of the media product is a bit complicated. On a superficial level, the article has many similarities with a printed 
article. However, there are several highlighted words (twenty in all) in the article, which function almost like footnotes in a printed text, meaning that when the reader follows such a hypertext link, he or she is redirected to another text. However, the function of a hypertext reference, as it is used here, and a footnote is not identical. Whereas the function of a footnote is, conventionally, to offer either a short additional remark and/or a specific reference, the hypertext link in a digital text instead redirects the reader to another article, which the reader gains access to by clicking. The reader can hit the back button on the browser to return to the "Climate change made Europe's 2019 record heatwave up to '100 times more likely" article, but he or she may get lost or simply become more interested in the new website, so it is possible that there is no return to the original article. Or, to speak in spatiotemporal terms, the hypertext affords a temporal and spatial sequence which differs from the rather strict and relatively simple spatiotemporal sequence of a printed article. The rather strict sequence of reading the conventional written article is broken up into a more fluid and potentially less restricted (in space and time) form. Compared to the limited length of a written article (ending when the article ends), the web article is potentially non-finite, at least if one follows the links to new links and more new links. It is worth mentioning that most of the hypertext references are 'in-house', so to speak, to CarbonBrief articles that go into more depth about some of the topics in the article.

The sensorial dimension of the digital article on the net does not differ significantly from that of a written text: the visual interface is perceived via the eyes. However, when clicking around in the article, bodily movement of the fingers on the keys or the mouse pad or on an external mouse is needed, which initiates a sensorial element of touch, too.

The semiotic aspect of the article combines in intricate patterns the three sign relations suggested by Peirce (as do most media products). The written text must be read as symbolic signs designating verbal language, whereas the photograph and the two visualizations must be read as two kinds of mainly, but not solely, iconic representations. The initial photograph iconically signifies extreme heat, represented by a male figure, whereas the two following visualizations consist of maps of Europe upon which coloured areas symbolically signify (by symbolic colour codes) the heat at a given moment in the summer of 2019 and, in the next map, the historic development of heatwaves from 1950 to 2018 as compared to the summer of 2019. Major aspects of the media product rely on the indexical sign function in the sense that many of the most important facts of the text 
as well as the visualizations are representations of indexical measurements, that is, natural scientific investigations with a variety of measuring instruments that are then collected and represented in the text.

The first, descriptive, part of the analysis can now be summed up. The general media type is the popular scientific journal article, which, more specifically, is technically displayed by way of computer screens or other electronic devices. This technical aspect leads directly into the material aspect relating to the very basic possibilities that an electronic text offers (in comparison with a printed text). Important here is the fact that, for economic reasons, a higher number of photographs and other illustrations can be included. Also, the hypertext possibilities, understood as part of the spatiotemporal set-up, are crucial when it comes to referring directly, via links, to other texts. In sensorial terms, human sight dominates, but touch is implied, too.

With this initial description of the media product, I hope to have exemplified that, even though such a description is rather banal, it has the potential to clarify one thing: that understanding the basic medial set-up of a media product conveys significant aspects of it, even before going into the elements of the text that the cultural sciences would normally feel more comfortable thinking about, namely the content and form aspects: what it is about and how is it formed.

\section{Step 2}

Based on the descriptions created during step 1, Step 2 is meant to involve a discussion of the general affordances of the media type, and in particular the specific media product, to prepare for a specific discussion of the general ecological question and the specific topic.

The popular scientific article, as a media type, is a classic example of science communication, and it partakes in what in science communication studies is understood as the "public understanding of science" (Burns et al. 2003). More specifically, the article is part of the field of environmental communication, which has exploded in recent years according to a literature review (Comfort and Park 2018).

The purpose of the article is to represent complex scientific research about findings in climate science in general, and about so-called attribution science in particular, to the general public. The article tries to cater for non-specialist readers and add to the public understanding of science, as mentioned above. This can be reformulated in intermedial terms; the writer of the CarbonBrief article, Daisy Dunne, conducts a media 
transformation by moving content or ideas from the medium of scientific article(s), which is the originating background or source, into the new media type, the popular science article. A basic rule of popular science communication of complex research results is to simplify them to make them understandable. Therefore, there is an immediate element in the media transformation that consists in picking out and 'translating' technical terms, highly formalized terminology, and numbers that are difficult to grasp into something else.

Simultaneously with simplifying and picking out material, the writer faces a more constructive task, namely to find appropriate ways to represent the ideas which have been researched in the natural sciences. In intermedial terms, this means that the media transformation aspect connects to the media integration aspect. The question of representing the facts of the scientific findings can be partly solved by choosing and combining different media aspects and modalities.

The most important combination aspect in the article is between-in Peircean terms - the signs that are mainly meant to be interpreted as iconic signs (the photograph and the two coloured maps) and the written text consisting of mainly symbolic signs. The written text dominates in the meaning making of the message (in the sense that the text could more or less stand alone and still be meaningful without the images- the opposite is not the case), but the iconic features are very important. The title of the article, written on top of the photograph, designates the entire article's content: climate change made Europe's 2019 record heatwave up to "100 times more likely". But it is also a complex verbal utterance: taking as its starting point the current heatwave, it connects the dramatic weather event to a larger historical trend and stresses the most important conclusion of the underlying research: that heatwaves are becoming more frequent and warmer as a result of global warming. In addition, the title contains a quote which has no author, although it will become clear where it comes from if one reads the article. The rest of the article substantiates this headline and supports the claim with the aid of three main forms of support: (a) quotes and reported quotes from researchers; (b) the material referred to in the hyperlinks, of which several are current measurements of the temperatures around Europe; $(c)$ visual material. The quotes and the material in the hyperlinks build up an argument using theoretical and historical claims combined with scientific measurements that together aim at producing the overall message, which has a narrative form: it starts from the individual experience (heatwave in London) and leads to a more 
general fact (heat all over Europe), which are both part of a more elaborate trend (heat in Europe over time). This is an argument that clearly goes from the specific to the general.

The iconic material, on the other hand, is effectively organized to support that narrative form. It starts from the individual, human-interest perspective in the first photograph and leads to the second map of Europe where the individual aspect of the first image is, so to speak, made a condition for many Europeans at the same time. Finally, with the second, historically oriented map, the current heatwave is seen as corresponding to a much more comprehensive pattern. The pictures tell a rudimentary story that supports, or, rather, doubles, the written text: the pictures 'say' that our individual experience must be taken seriously (photograph of man in heatwave), but that the heatwave was probably more than a mere coincidence-it was a European phenomenon (first map). Not only that, but the extreme weather can be explained by referring to historical climate models (second map), which give the initial individual experience a totally new meaning.

The use of hyperlinks in the text is another combination aspect that I have already mentioned but which should now be understood in more depth. It should come as no surprise that the technical and material aspect of a text has effects on its meaning production, but in this case in particular the spatiotemporal nature of the digital text has certain effects, which are best understood by comparing it to a conventional printed news article. Generally, and on the positive side, the journalist producing a digitally disseminated text can use coloured illustrations and photographs to accompany the text without incurring large additional costs and without technical problems or limits because of space, as compared to a printed article in a journal. From the point of view of the reader, this use of visual material may make the reading easier and more pleasurable. Apart from the overall graphic layout of the article, made possible by the digital platform, a digital text like this facilitates an easily navigated reference system to other digital texts, including references to other media (the BBC, for instance) as well as meteorological sites and scientific texts. Also, in order to avoid explaining all the scientific background facts, the CarbonBrief article includes several 'internal' references, that is, references to earlier articles by CarbonBrief. Finally, the article ends by referring to related articles where the points being made can be deepened or discussed.

Making references to other news outlets or to already published material is not unique to the affordances that the specific technical media aspect 
of digital journalism allows: the point is that reaching these references only takes one click.

The final feature that distinguishes this article from a printed text is the fact that readers can comment on the text immediately; CarbonBrief employs a feedback system called Disqus, which prevents anonymous comments and only allows so-called comments from registered users. In the case of this particular article, at the time of writing (7 September 2019, a month after the publication of the text), only two comments accompanied the text: both were critical of the content of the article. Again, several of these features exist in a printed article in a newspaper or a journal or magazine. The difference is that the illustrations in the online article are cheaper to reproduce, the references to very comprehensive material outside the text can be much more elaborate and easier to get to, and the comments from readers are directly included alongside the article in its present state instead of being, in a printed newspaper, part of a later edition one or several days later, where the readers' comments stand alone without the originating debated text.

There are also limitations to this media type compared to a text in a printed newspaper. First of all, this article is relatively brief in terms of the number of words it contains, which may be part of the strategy of CarbonBrief to make their climate news both understandable and digestible, and although the length is limited, the breadth of material that the hyperlinks connect to makes the article almost infinite in size. Second, a downside to using hyperlinks is that the writer risks 'losing' the reader as he or she is making their way through the article if the reader follows one of the links and does not return to the originating article.

After this long descriptive analysis of the intermedial aspects of the article, it is now possible to offer a more interpretative answer to the questions I posed initially:

(a) How, from an intermedial point of view, do the media products represent scientific research related to global warming?

(b) How, from an intermedial point of view, do the media products employ strategies that make hard science directly related to the everyday experience of non-experts in climate science?

In response to (a), when it comes to the representation of scientific research, I have already pointed to the obvious fact that the CarbonBrief article simplifies the research to a level at which it can be understood by 
non-specialists. This means that complicated terminologies, comprehensive methodological discussions, and large datasets (or thorough descriptions of these) are not included in the article. The brevity of the article (as compared to most standard scientific articles) is a sign of this. The use of hypertext links retains the brevity of the article while offering more indepth material to readers who are interested, for personal or professional reasons, in having both the ideas and the references as further information. The article manages, in the short space it occupies, to refer to the fundamental method of 'attribution science' as compared to climate science's normal approach, and this gives the reader a feeling that the sciences are not static but are evolving, indeed progressing. The graphic style of the article (which is a typical intermedial phenomenon in itself, since it considers the visual set-up of the page, the layout, etc.) gives the article an appealing look that makes the reader feel invited to take part in the content.

A large part of the appeal of the article has to do with the use of images: the first photograph makes the article directly link to related experiences that many Europeans (and others) have had both in 2019 and in 2018. And, as mentioned already, the three image sections of the article not only illustrate the article but also 'tell' a little story themselves while, at the same time, they give the article 'space' and 'air', which is part of its inviting style.

In response to (b), the images are part of the article's attempt to not only represent a 'readable' version of complicated scientific research but also to make the research relevant for non-specialists. Here, the initial photograph, in particular, is a hook; for many readers, experiences of extreme heat are familiar, and instead of focusing on the anecdotal aspects or the personal feelings of isolation that the heat causes (which is the angle of many mainstream reports on heatwaves), this article uses a personal experience first, but then makes it a much more widespread feeling, first on a European level (i.e., in space) and later on the level of a long historical period (i.e., in time).

\subsubsection{Charlotte Weitze's Novel Den afskyelige (The Abominable)}

Because of spatial restraints, I will offer a shorter version of the descriptive analysis of the second media product than of the first one, but this will still make a comparison possible. 
First, I need to present the media product. Charlotte Weitze's 320page novel Den afskyelige (The Abominable) (Weitze 2019) is narrated by Heidi, a young nurse living in northern Scandinavia, probably Norway, in a relatively near future dominated by global warming. She tells the dramatic story of how she falls in love with a man, Kenneth, who is apparently suffering from hyperhidrosis, which is abnormal sweat production, and she describes in detail how the couple struggles, with mixed results, to live a $\mathrm{CO}_{2}$-neutral life in a globally warmed and warming world. Later in the novel, the reader understands, and so does Heidi, that her lover Kenneth has no conventional diagnosis: instead his many symptoms stem from the fact that he is actually a descendant of a yeti. She leaves her lover, despite being pregnant, but later loses the foetus. After a dam collapses towards the end of the book, she hides on a mountain while trying to save her best friend, Mette, and her baby. However, Mette drowns in the rising waters and the book ends with Heidi taking care of the little baby, not knowing whether the mountain top on which they live is the only place on earth where it is still possible to survive.

It is clearly a novel that deals with global warming, but in an entirely different register from that of the article previously discussed. It will hopefully be possible to define the differences more precisely by way of an intermedial analysis.

\section{Step 1}

Step 1 of this shortened analysis will just briefly establish the basic medial facts about the novel. Regarding the technical media of display dimension, I read the work in a hardback printed book version; the book has a dust cover with an illustration that is identical to the one on the hard cover (designed by Alette Bertelsen), which combines verbal language with the dark profile of a looming animal figure while also alluding to a mountain with a tiny house on top, thus referring to the end of the novel.

The basic material dimension of the novel is printed letters on paper pages, and the spatiotemporal set-up is that of most of narrative written literature (see Bruhn (2016): a forward sequence is suggested even though one can indeed read a novel from the end and towards the beginning or read it at random places. Besides turning the pages and holding the book, which requires the sense of touch, the most important sensorial aspect when reading a novel is of course using our eyesight to read. Apart from the dust cover, the dominating semiotic nature of the novel is the symbolic, linguistic sign function. 
There are, to use Elleström's terminology (2020), qualifying and contextual dimensions which place this book solidly in the tradition of written, narrative literature: the generic form of the novel (roman in Danish) is stated on the cover and on the title page. However, this is very unusual for a novel, at the end of the book, the reader finds a page of acknowledgements, thanking funding agencies and colleagues. In addition, Weitze extends her thanks to a number of experts in many different fields including disaster research, psychiatry, and studies of fanaticism and religious beliefs. These experts contributed to her 'research for an open microphone' for a radio show on Danish broadcast Radio 24syv.

To sum up the first step: it is not difficult or surprising to categorize Den afskyelige as a written narrative novel; the question is how to analyse it from an intermedial perspective.

\section{Step 2}

How then, in the second step, can the text be analysed from an intermedial point of view, including the fundamental axes of media transformation and media integration? Let me discuss the media transformation first.

Because it is an ecomedia product, the entire novel can be said to be a media transformation of already existing ideas concerning the ecological crisis and global warming, as this has been put forward in a huge network of scientific, political, and popular scientific material.

I mentioned that the novel has an (for literary fiction) unusual list of acknowledgements that includes not only friends, colleagues, and funding agencies but also a number of experts in several fields. Weitze thus explicitly acknowledges that several aspects of the novel must be seen as media transformations from the fields of climate science, engineering (concerning dams), and fanatical (religious) psychological states, among others. From this point of view, it would be possible to analyse a number of specific scenes in the book, as well as the overall theme of the book as the intermedial interplay between medium specificity and transmedial subjects (which was a way of defining the study of media transformation, as mentioned above). In other words, it would be possible to identify which aspects of the forms and contents of the originating texts that may be transformed (the transmedial aspects) and which aspects that are only transported with greater difficulty (because of medium-specific constraints). To exemplify briefly: the detailed research results of a scientific article cannot be referred to at length in the novel, but the two protagonists can discuss why it is that a vegetarian diet is much more 
climate-neutral than consuming meat (Weitze 2019: 162-163). Therefore, almost everything in this novel, from the overall thematic content to many detailed discussions and particular scenes of the novel, might be analysed as instances of media transformations from a number of scientific disciplines into the supposedly fictive set-up of the novel.

Regarding the media integration analysis, there are different ways to pursue this. For instance, it would be interesting to analyse the ways in which the novel represents media products from the mass media, how mass media products stand up against other medial representations, and how this particular relation influences the protagonists. One could also investigate the way in which old written notes and photographs from Heidi's past are interpreted as signs of a changing climate and the death of Heidi's sister in an accident when Heidi was a child. These notes and photographs stand in stark contrast to the media products that Heidi and Kenneth produce together: they create pornographic films in order to make money for their $\mathrm{CO}_{2}$-neutral life. This peculiar media practice may be discussed while also participating in what Stacy Alaimo has discussed as independent, alternative and partly joyful activist outlets' (pornproducers!) way of engaging with the environmental debate (Alaimo 2016).

After this brief intermedial analysis of the novel, it is now possible to discuss the novel in relation to the two questions:

(a) How, from an intermedial point of view, do the media products represent scientific research related to global warming?

(b) How, from an intermedial point of view, do the media products employ strategies that make hard science directly related to the everyday experience of non-experts in climate science?

In response to (a), when it comes to representing scientific research in Den afskyelige, the aim of the novel is to represent and simplify the research at the same time to a level at which it can be understood by non-specialists.

The main strategy of incorporating or representing scientific material in a work of fiction, a novel, is to embody it into the standard aspects of the narrative fiction. In this case, this takes place in at least two very typical ways. First, the entire storyworld of the imagined future world is informed by contemporary scientific theories and simulations concerning what the world will look like in a future affected by global warming. Second, many of the discussions of the protagonists relatively directly translate scientific material into actions, reflections, and direct conversations or discussions. 
In this way, one of the typical medial aspects of scientific discourse-the attempt to produce a non-subjective discursive style that tries to express the non-subjective character of the scientific research-is directly opposed in this novel. Or, to formulate this differently, everything in a novel must be seen or described from the perspective of human beings, in this case Heidi, who is the narrator of the novel, and the characters of the fiction that she narrates. If the ideal of natural science is to produce knowledge that can be repeated by other researchers, who are usually anonymous, in controlled experiments or measurements, the golden rule of fiction is quite the opposite: to always embody everything that happens through the minds and bodies of narrators and/or characters; in fiction there is no attempt at objectivity in the scientific sense of the word.

From this comes an answer to (b), my second research question: how do the media products employ strategies that make hard science directly related to the everyday experience of non-experts in climate science? What fiction does in its partly imagined, partly scientifically grounded storyworlds is to produce human figures who experience on their bodies and in their minds the more concrete but imagined conditions that are argued for by natural scientific articles. If the aim of natural scientific media products is to predict possible future worlds, in this case including the effects of global warming, the job of fictional storyworlds is to concretize and embody scientific research into very recognizable specific situations. In this way, the results produced in natural science becomes directly recognizable and understandable for readers who either do not wish to or are not able to read scientific articles. This means that the reader of Den afskyelige is helped to experience, via the fictional storyworlds, what life might feel like in the future; Charlotte Weitze offers an interpretation of what she believes, according to research, to be future scenarios for a life in the Anthropocene.

\subsubsection{Comparison of Article and Novel}

\section{Research Question 1 (Representation of Science)}

The comparison between the two texts follows the two research questions. The first research question has to do with the ways in which the two media products represent the scientific research results that in both cases constitute an important source behind the texts. 
Here, the most important difference is probably that the CarbonBrief text directly paraphrases, refers to, and quotes science, whereas the novel has a much more indirect way of referring to the scientific research. In Weitze's novel, science is constantly being put in the mouths of the protagonists, in direct conversations and discussions and in more general references to 'science says' or 'new research demonstrates'. To explain it in a different way, there is a basic narratological distinction between the texts: the CarbonBrief author functions as an explicit narrator who states the scientific facts, also by referring directly to quotes from scientists, but Weitze's novel is organized in such a way that the scientific results and theories per definition are put in the mouths of persons inside the storyworld.

Another clear difference is that the CarbonBrief article, starting with the discussion about actual weather phenomena, is particularly interested in making predictions about the future. Weitze's novel, on the other hand, is set in such a future, but a fictive future; however, the people inside the storyworld do not, of course, experience the world as a future, but as their present living conditions and surroundings.

This means, and this more or less sums up the points about direct/ indirect and future/present, that the popular science article, like science, aims at producing general notions about the ecological crisis and global warming. The novel, on the other hand, individualizes the scientific, generalized notions of the future risks inherent in the Anthropocene condition.

I have chosen two media products in two qualified media types that are both successful in many ways in what they are doing, at least if the criteria are their abilities to represent scientific results and theories in their respective media forms. However, when comparing the communicative efficiency (regarding the article) or the aesthetic form and content (regarding the novel) criteria, it is clear that these could be more critically evaluated regarding their representation of science. The article could, for instance, be criticized for taking an unproblematized Eurocentric view on the Anthropocene future; this, presumably, has to do with the fact that Britishbased CarbonBrief, while having a good European and global outlook, nevertheless functions inside a distinct UK context, which explains the choice of first a photo from London and then the two European maps (as opposed to more global possibilities). Regarding a critical approach to the novel, it would be absurd to criticize the novel for only representing a limited, Eurocentric aspect of the global effects of the Anthropocene condition. 
From a medium-specific perspective, a novel tends to be anchored in time and space almost by the logics of medium specificity: generally, the raison d'être of fiction is to not speak in generalities but, on the contrary, to demonstrate how general social or scientific rules work on a human scale, that is, in the concrete lives of individuals or individuals as part of social groups. Therefore, if one has to criticize the novel, it should be on aesthetic grounds. A well-known aesthetic ideal is that when science (or philosophy or other external forms) 'enters' art it should do so in ways that mean that the science is introduced in the artistic universe in necessary or elegant or inconspicuous ways (for an example of this position as well as an historical discussion of the idea, see Gadamer 2013 [1960]). This is not always the case in Den afskyelige, where some conversations (or individual utterances in dialogues) sometimes read as almost direct quotes from newspapers or scientific journals without being properly incorporated in the novelistic form as natural, spoken language uttered in a conversation between two human beings. In these instances, the science is shoehorned into the fiction, so to speak: the author's comprehensive research enters the novel as research and not as aesthetically motivated form and content.

\section{Research Question 2 (Scientific Results and Everyday Experience)}

It is of course impossible to completely keep apart the first research question (representation of science) from the second question, which has to do with how the two media products employ strategies that make science directly related to the everyday experience of non-experts in climate science.

Communication, according to how it is normally defined, relates to the receivers of the communicative activity. Therefore, my admittedly slightly crude starting point was that one of the major targets, for both popular science communication and a mainstream novel focused on climate change, is transferring aspects of climate science results from hardcore science environments into new areas. Doing this also has to do with relating the scientific ideas to everyday experiences to a certain extent, and both the article and the novel clearly attempt to do this.

Global warming, and most of the other effects of the critical ecological situation, are, as implied by their names, global in scope, and this is undoubtedly one of the reasons why relating these issues to specific, personal experience is not always an easy task. Nevertheless, I have chosen 
these two media products as examples of successful attempts to do so, and that is why my research does not ask if but how they do it.

The article's approach to this, as I have emphasized, is to base the global condition on a local phenomenon: the specific heatwaves described in the text and represented by photography are used as signs of a global warming tendency. So, the heatwaves, which many people in Europe have relatively fresh memories of, were not only problematic for one person (the person in the photo) but also for many others who can easily identify with him, and supposedly for the entire European population who are, as shown via the maps of Europe, experiencing this warming. The man in the photograph and the maps are characterized by anonymizing - the idea is that anybody will be able to identify with the man and the nations, and the goal of the article is to make the general point, most of all on a cognitive level; for all we know, the man might be an actor and the maps are extremely general.

Again, the novel's strategy is distinctly different: it offers ways of very directly understanding what life might be like in a warmer world, not in general terms, but by way of identifying fully with specific persons with names, a fictional background, bodies, families, and jobs. Presumably, the intention of the author is that such a concretized, specific description is a powerful way to make readers understand how it feels (in both the psychological and the sensorial sense of the word) to live in such an Anthropocene future. Needless to say, the pattern from the first research question returns here. It is a question of the generality of science versus the specificity of arts and literature.

\subsection{CONCLUding Remarks}

My impetus for writing this article is far from original: it stems from the well-known observation that the natural sciences produce knowledge and data which are absolutely crucial for the world to know about and act upon-but that the transfer of scientific knowledge to the general public is neither unproblematic nor simple. From this basic fact followed an identification of a gap in the broad field of environmental humanities concerning this question, and also in the social scientific fields investigating, for instance, risk, health, and science communication. As far as I have been able to establish, these fields have not developed the abstract theoretical ideas or the specific methods to deal with the plethora of different specific media products or the more generic qualified media types that deal with 
these questions. I have not come across a scientific approach which is able to effectively handle the problems involved in describing, analysing, interpreting, and finally comparing radically different media products from completely different media backgrounds, even if they are representing clearly comparable scientific content.

Having first identified this problem, I then tried to suggest a theory and method called intermedial ecocriticism which, as the name suggests, combines two different research fields and traditions, namely intermedial studies and ecocriticism. Because it is part of environmental humanities, one of the main strengths of ecocriticsm is its deep understanding of the historical aspects and the critical level of the ecological crisis. As a research field, intermedial studies, on the other hand, has a thorough understanding of the problems and complexity of representation in general, and, in particular, intermedial studies has developed tools to analyse comparable content and forms in different media.

I tried to sketch out briefly some of the most important aspects of the two scientific fields before I then ventured to propose an analytical method that borrows, so to speak, the focus on ecological issues from ecocriticism and the focus on representational issues across media from intermedial studies. I suggested analysing and comparing ecomedia products in two consecutive analytical steps, which led to a comparison of, in this case, an online popular scientific article and a novel. I tried to conduct the comparison by establishing two specific questions, one regarding how the media products represent scientific research regarding climate change, and the other regarding how the ecomedia products relate the scientific results to the everyday non-specialist experience.

When doing comparative analysis across media, it is tempting to end up on an evaluative or even competitive note: which media product is 'best' at doing $x$ or $y$ ? Given the fact that what I refer to as 'weak' or 'temporary' medium specificity does exist, such questions are not uninteresting, and it is easy to see that some media are, in general terms, more suited to represent certain things than other media. It would, for instance, be rather difficult (but not totally impossible) for the otherwise highly developed and utterly sophisticated medium of symphonic classical orchestral music to express, clearly and unambiguously, the three major changes made in the state budget of the Swedish state from 2018 to 2019-whereas that would be relatively easy to do in a short, written journal article in a daily newspaper. 
In the case study examples that I had selected for my investigation, I was not really able to identify such obvious differences in the 'success' of representing the two issues I had focused on. That might be because I had chosen two media products that were in fact relatively similar (they are both examples of narratively ordered material in which the predominant basic modality is written language), but that was not really what I had expected to accomplish with my analytical method. Instead, what the method was able to detect were some relative but not very dramatic advantages accomplished by, respectively, the science journalist Daisy Dunne and the fiction writer Charlotte Weitze; these advantages were to a large degree dictated by the 'weak' medium-specific affordances of the qualified media they worked in.

It became clear that both Dunne and Weitze had obviously worked intensively to incorporate natural scientific research into their texts. The main difference was the way in which the article tries to refer directly and unambiguously to ongoing scientific research and sources, whereas the novel needs to transfer the scientific research from direct references into either (a) a general construction of a future, fictional world dominated by global warming or (b) speech in the mouths of the protagonists when they discuss how to live in such a world. From a superficial point of view, the popular scientific article perhaps could be thought to be much better suited to doing this, but I have tried to demonstrate that Weitze has managed to include quite a lot of scientific material in her novel (as was clear from her mentioning numerous scientific expert sources at the end, too).

When it comes to relating the science to everyday experience (my second question), the novel, following conventional wisdom, probably 'ought' to do best at this. By working with fictional persons in recognizable but fictional surroundings, it should be easy for a novelist to make science matter to non-scientists. Weitze did not fail at this task, but even the journalist Dunne shrewdly used the medium-specific available means of the online popular science article to construct a small narrative consisting of a man in the not-forgotten local heatwave of 2018 in London that circled outwards to a European climate condition that was easy for many readers to identify with. Banalizing my subject a little bit, I conclude that it was a draw between Weitze's somewhat surreal cli-fi novel and Dunne's narratively ordered popular science article.

However, even if this competition ends in a draw, I do hope that perhaps the idea of an intermedial ecocriticism might be a winning concept. I maintain that we need tools to analyse and discuss the scientific research 
regarding our epoch's most alarming topics, and even if we in the humanities cannot conduct the natural scientific research ourselves, we can certainly contribute to the thinking about the ecological crisis in crucial ways - in particular by investigating all the different media products, in all the different media types, that do the difficult work of transporting scientific material across the media borders to where most people learn what the sciences are doing.

\section{Notes}

1. For a recent literature review of some of these fields, see Chadwick (2017).

2. Many individual media types outside literature have been under ecocritical (in the broad sense of the word) scrutiny, for instance, film studies (Kaplan 2015), visual art (Brenthel 2016; Demos 2017), music (Allen and Dawe 2016; Hart 2018), and design (Sherin 2013) — to mention just some of the more recent publications in a rapidly expanding field.

3. In earlier publications, I have used a general distinction between media combination and media transformation, but here I follow Elleström's new terminology (2020).

4. I have critically discussed Morton's notion of hyperobjects in Bruhn (2018).

\section{REFERENCES}

Alaimo, Stacy. 2016. Exposed: Environmental Politics and Pleasures in Posthuman Times. Minneapolis: University of Minnesota Press.

Allen, Aaron S., and Kevin Dawe, eds. 2016. Current Directions in Ecomusicology: Music, Culture, Nature. New York, NY: Routledge.

Allen, Graham. 2011. Intertextuality. 2nd ed. London and New York: Routledge. Atwood, Margaret, Mark Martin, and Bill Mckibben, eds. 2011. I'm with the Bears: Short Stories from a Damaged Planet. London: Verso.

Brenthel, Adam. 2016. The Drowning World: The Visual Culture of Climate Change. Lund: Department of Arts and Cultural Sciences, Lund University.

Bruhn, Jørgen. 2010. Heteromediality. In Media Borders, Multimodality and Intermediality, ed. Lars Elleström, 225-236. Basingstoke: Palgrave Macmillan.

- 2016. The Intermediality of Narrative Literature: Medialities Matter. Basingstoke: Palgrave Macmillan.

- 2018. Ecology as Pre-text? The Paradoxical Presence of Ecological Thematics in Contemporary Scandinavian Quality TV. Journal of Aesthetics \& Culture 10: 66-73.

Bruhn, Jørgen, and Anne Gjelsvik. 2018. Cinema Between Media: An Intermediality Approach. Edinburgh: Edinburgh University Press. 
Bruhn, Jørgen, Anne Gjelsvik, and Eirik Frisvold Hanssen, eds. 2013. Adaptation Studies: New Challenges, New Directions. London: Bloomsbury.

Burns, T.W., D.J. O'Connor, and S.M. Stocklmayer. 2003. Science Communication: A Contemporary Definition. Public Understanding of Science 12: 183-202.

Chadwick, Amy E. 2017. Climate Change Communication. Oxford Research Encyklopedia, Communication. https://doi.org/10.1093/ acrefore/9780190228613.013.22.

Comfort, Suzannah Evans, and Young Eun Park. 2018. On the Field of Environmental Communication: A Systematic Review of the Peer-Reviewed Literature. Environmental Communication 12: 862-875.

Demos, T.J. 2017. Against the Anthropocene: Visual Culture and Environment Today. Berlin: Sternberg Press.

Dunne, Daisy. 2019. Climate Change Made Europe's 2019 Record Heatwave up to '100 Times More Likely. CarbonBrief. https://www.carbonbrief.org/climate-change-made-europes-2019-record-heatwave-up-to-hundred-timesmore-likely. Accessed 4 February 2020.

Elleström, Lars. 2010. The Modalities of Media: A Model for Understanding Intermedial Relations. In Media Borders, Multimodality and Intermediality, ed. Lars Elleström, 11-48. Basingstoke: Palgrave Macmillan.

- 2020. The Modalities of Media II: An Expanded Model for Understanding Intermedial Relations. In Beyond Media Borders: Intermedial Relations among Multimodal Media, Volume 1, ed. Lars Elleström, 3-91. Basingstoke: Palgrave Macmillan.

Estok, Simon C. 2017. Virtually There: "Aesthetic Pleasure of the First Order," Ecomedia, Activist Engagement. ISLE: Interdisciplinary Studies in Literature and Environment 24: 4-21.

Gadamer, Hans-Georg. 2013 [1960]. Truth and Method. London: Bloomsbury Academic.

Garrard, Greg. 2012. Ecocriticism. 2nd ed. London: Routledge.

Hall, Stuart, Jessica Evans, and Sean Nixon, eds. 2013. Representation. London: SAGE.

Hart, Heidi. 2018. Music and the Environment in Dystopian Narrative: Sounding the Disaster. Basingstoke: Palgrave Macmillan.

Heise, Ursula K., Jon Christensen, and Michelle Niemann, eds. 2017. The Routledge Companion to the Environmental Humanities. London: Routledge.

Hutcheon, Linda. 2006. A Theory of Adaptation. London: Routledge.

Kaplan, E. Ann. 2015. Climate Trauma: Foreseeing the Future in Dystopian Film and Fiction. New Brunswick, NJ: Rutgers University Press.

Kress, Gunther. 2010. Multimodality: A Social Semiotic Approach to Contemporary Communication. London: Routledge.

Mitchell, W.J.T. 1994. Picture Theory: Essays on Verbal and Visual Representation. Chicago: University of Chicago Press. 
Morton, Timothy. 2013. Hyperobjects: Philosophy and Ecology after the End of the World. Minneapolis: University of Minnesota Press.

Nixon, Rob. 2011. Slow Violence and the Environmentalism of the Poor. Cambridge, MA: Harvard University Press.

Roundtree, Aimee Kendall. 2014. Computer Simulation, Rbetoric, and the Scientific Imagination: How Virtual Evidence Shapes Science in the Making and in the News. Lanham: Lexington Books.

Rust, Stephen, Salma Monani, and Sean Cubitt, eds. 2016. Ecomedia: Key Issues. London and New York: Routledge.

Sherin, Aaris. 2013. Sustainable Thinking: Ethical Approaches to Design and Design Management. London: Fairchild Books.

Steffen, Will, Johan Rockström, Katherine Richardson, Timothy M. Lenton, Carl Folke, Diana Liverman, Colin P. Summerhayes, Anthony D. Barnosky, Sarah E. Cornell, Michel Crucifix, Jonathan F. Donges, Ingo Fetzer, Steven J. Lade, Marten Scheffer, Ricarda Winkelmann, and Hans Joachim Schellnhuber. 2018. Trajectories of the Earth System in the Anthropocene. Proceedings of the National Academy of Sciences 115: 8252-8259.

Weik von Mossner, Alexa. 2017. Affective Ecologies: Empathy, Emotion, and Environmental Narrative. Columbus: Ohio State University Press.

Weitze, Charlotte. 2019. Den afskyelige. Copenhagen: Samlerens Forlag.

Yusoff, Kathryn, and Jennifer Gabrys. 2011. Climate Change and the Imagination.

Wiley Interdisciplinary Reviews: Climate Change 2: 516-534.

Open Access This chapter is licensed under the terms of the Creative Commons Attribution 4.0 International License (http://creativecommons.org/licenses/ by $/ 4.0 /$ ), which permits use, sharing, adaptation, distribution and reproduction in any medium or format, as long as you give appropriate credit to the original author(s) and the source, provide a link to the Creative Commons licence and indicate if changes were made.

The images or other third party material in this chapter are included in the chapter's Creative Commons licence, unless indicated otherwise in a credit line to the material. If material is not included in the chapter's Creative Commons licence and your intended use is not permitted by statutory regulation or exceeds the permitted use, you will need to obtain permission directly from the copyright holder.

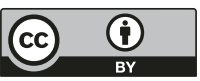

